\title{
Strontium Oxide Decorated Iron Oxide Activated Carbon Nanocomposite: A New Adsorbent for Removal of Nitrate from Well Water
}

\author{
Mohammad K. M. Nodeh, ${ }^{a}$ Gholamreza N. Bidhendi, ${ }^{a}$ Mohammad A. Gabris, ${ }^{b}$ \\ Behrouz Akbari-adergani, ${ }^{\circledR} *, c$ Hamid R. Nodeh, ${ }^{d}$ Aliakbar Masoudi ${ }^{a}$ and \\ Syed Shahabuddin*,e
}

${ }^{a}$ Department of Environmental Engineering, Faculty of Environment, University of Tehran, Tehran, Iran

${ }^{b}$ Department of Chemistry, Faculty of Science, University of Tehran, Tehran, Iran

'Nanotechnology Products Laboratory, Food and Drug Laboratory Research Center, Food and Drug Administration, Ministry of Health and Medical Education, Tehran, Iran

${ }^{d}$ Department of Food Science \& Technology, Faculty of Food Industry and Agriculture, Standard Research Institute (SRI), Karaj, Iran

${ }^{e}$ Research Centre for Nano-Materials and Energy Technology (RCNMET), School of Science and Technology, Sunway University, 47500 Selangor Darul Ehsan, Malaysia

In the present study, activated carbon was magnetized by iron oxide and modified by strontium based nanoparticles (FeAC@ $\mathrm{Sr}$ ) to introduce it as an efficient favorable adsorbent for the removal of nitrate ions from underground water. The decorated adsorbent was characterized in terms of size, structure, morphology and composition using scanning electron microscopy, Fourier-transform infrared spectroscopy and energy dispersive X-ray spectroscopy. The equilibrium adsorption data were well fitted and explained by Langmuir isotherm with a maximum adsorption capacity of $87.42 \mathrm{mg} \mathrm{g}^{-1}$ (theoretical value calculated from the Langmuir isotherm model). Regarding adsorption kinetic it was seen that it is fit for pseudo-second-order process with an equilibrium state which was reached at $\mathrm{pH} 4.0$ in $90 \mathrm{~min}$. The results also revealed that the incorporation of positively charged strontium and iron oxide into the activated carbon has triggered removal efficiency for the negatively charged nitrate ions.

Keywords: activated carbon, iron oxide nanoparticles, nitrate ions removal, adsorption equilibrium, adsorption kinetic

\section{Introduction}

The presence of some organic and inorganic compounds in water is a crucial factor affecting water quality. Continuous discharge of pollutant agents in water receiving resources causes an increase in their concentration, and can be very dangerous for the human health. ${ }^{1,2}$ Nitrate is a worldwide problem and one of the potentially inorganic contaminants with increasing concern in supplying safe portable water. ${ }^{3}$ The high solubility of nitrate in water results in its easy leakage and its wide contamination impact in return. ${ }^{4}$ Large amounts of nitrate can cause water pollution leading to eutrophication and oxygen depletion of water body as well as harmful

*e-mail: analystchemist@yahoo.com; syedshahab.hyd@gmail.com health effects such as blood disorders and some cancers through producing carcinogenic nitrosamines. ${ }^{5}$ Additionally, some adverse effect of excess nitrate in water resources are including growth of algae, teratogenic effects on fish and animals as well as infant methemoglobinemia. ${ }^{4,5}$ Nitrate concentration as specified by World Health Organization (WHO) should not exceed $50 \mathrm{mg} \mathrm{L}^{-1}$ within drinkable pure water. ${ }^{6}$ Many techniques have been reported for removal of nitrate from drinking water, but adsorption seems to be the most feasible technique due to its low cost, easy access, and being suitable for targeting soluble substances in solutions. ${ }^{7,8}$ Adsorption based on activated carbon (AC) is an efficient and simple method for the removal of nitrate from aqueous environments. ${ }^{9} \mathrm{AC}$ is a widely available porous material with large surface area into which nitrate anions can easily 
diffuse and trapped, ${ }^{10}$ however, it suffers from limited activated sites, and has a hard regeneration process. AC is considered as a stable supporting material that is compatible with wide range of materials. After bonding with some metal oxides such as iron oxide, the AC could be recovered and restored easily. Earth metal oxides, such as strontium oxide, are the promising materials for water treatment as they are positively charged self-supported nano assemblies tending to adsorb extremely low concentrations of anionic analytes and can be integrated easily. The considered assemblage provides facile decontamination of nitrate from the environment. ${ }^{5,11-13}$ Meanwhile combining the iron based materials to activated carbon reduces aggregation of the decontaminant phase and thus enhances its adsorption efficiencies. ${ }^{14}$ Iron groups of nanomaterials such as zero-valent iron, magnetite $\left(\mathrm{Fe}_{3} \mathrm{O}_{4}\right)$, and iron oxide $\left(\mathrm{FeO}_{\mathrm{X}}\right.$, $\mathrm{FeO}, \alpha-\mathrm{Fe}_{2} \mathrm{O}_{3}$ ) are used in many magnetic applications. ${ }^{15,16}$ The application of iron oxide based nanomaterials in nitrate removal is highly recommended because of its simple operation and low cost. ${ }^{17-19}$ Its small size enhances dispersion of magnetic nanoparticles while its large surface area provides rapid and efficient contaminants removal. ${ }^{20}$ In addition, it was revealed that iron oxide can increase the stability of the whole nanocomposite, occupies the pores of the activated carbon, prevents self-aggregation and oxidation, enhances the adsorption rate and facilitates the adsorption of analytes by the oxide shell via electrostatic interactions. ${ }^{21}$ The $\mathrm{Sr}-\mathrm{OH}$ terminated surface is $\mathrm{pH}$ dependent thus its adsorption capability can be altered upon change of $\mathrm{pH}$ or by further functionalization of its surface. ${ }^{22}$ Strontium oxide and iron oxide nanoparticles are known for being nontoxic and biocompatible..$^{23-27}$

Herein a simple and novel nanocomposite based on iron oxide doped activated carbon and strontium oxide (FeAC@Sr) was synthesized and applied for the removal of nitrate ions from well water. This study was also carried out to survey the adsorption kinetic and isotherm modeling of nitrate uptake onto FeAC@Sr. Hence, modification of porous activated carbon with magnetic iron $\left(\mathrm{FeO}_{\mathrm{x}}\right)$ and positively charged strontium with a synergic effect for the efficient removal of negatively charged nitrate ions was conducted. ${ }^{24,28-30}$ To the best of our knowledge this is the first study that reports such a nanocomposite material as an adsorbent for nitrate removal.

\section{Experimental}

\section{Materials and reagents}

Commercial activated charcoal was provided by Beijing Chemicals Co. (Beijing, China). All chemicals including sodium borohydride, sodium hydroxide, ferric chloride hexahydrate, hydrochloric acid and strontium nitrate used in synthesis of nanocomposite were purchased from Merck (Darmstadt, Germany) with a high analytical grade (> 99\% purity). Nitrate stock solution $\left(1000 \mathrm{mg} \mathrm{L}^{-1}\right)$ was prepared in deionized water. The working standard solutions of nitrate were prepared by proper dilution of the stock solution in deionized water. Well water with intrinsic $47 \mathrm{mg} \mathrm{L}^{-1}$ nitrate concentration was obtained from south of Tehran (the capital of Iran).

\section{Instruments}

A MIRA3 TESCAN field emission scanning electron microscope (FESEM; Prague, Czech Republic) was used to observe the morphology and crystallographic structure of the synthesized FeAC@ Sr nanocomposite. The functional groups of FeAC@Sr were analyzed using Equinox 55 FT-IR spectrometer (Bruker, Bremen, Germany) operating at 450 to $4000 \mathrm{~cm}^{-1}$ range to record the Fourier transform infrared (FTIR) spectra. Philips X-ray diffractometer (XRD) was used for crystalline pattern of the nanocomposite in the range of $2 \theta$ angle range from 10 to $80^{\circ}$. Belsorp-mini II (Osaka, Japan) BET (Brunauer-Emmett-Teller) analyzer was used for specific surface area of $\mathrm{FeAC} @ \mathrm{Sr}$ based on $\mathrm{N}_{2}$ gas adsorption-desorption at $350^{\circ} \mathrm{C}$ for $3 \mathrm{~h}$. Surface charges of the FeAC@Sr were analyzed with HORIBA SZ100Z zeta potentiometer (Piscataway, NJ, USA). Magnetic properties of the magnetic-FeAC@Sr were studied in terms of vibrating sample magnetization (VSM) using Megnatis Dagig Kavir magnetometer (Kashan, Iran).

\section{Synthesis of the magnetic nanocomposite}

The synthesis of nanocomposite was carried out based on the previously reported study ${ }^{18}$ with some modifications mainly via reduction of ferric iron $\left(\mathrm{Fe}^{3+}\right)$ with sodium borohydride. The procedure can be summarized as follows: exactly $3.0 \mathrm{~g}$ of activated charcoal was mixed with $1.5 \mathrm{~g}$ of $\mathrm{FeCl}_{3} \cdot 6 \mathrm{H}_{2} \mathrm{O}$ in a $4: 1(\% \mathrm{v} / \mathrm{v})$ ethanol/water mixture. Then an aqueous solution of $\mathrm{NaBH}_{4}(1.3 \mathrm{~g})$ was prepared in $100 \mathrm{~mL}$ water and added drop wise (1 drop every $2 \mathrm{~s}$ ) into the mixture. The mixture was then stirred for $45 \mathrm{~min}$ and the FeAC suspension was collected via a magnet, washed at least three times with water/ethanol and lastly oven dried at $80{ }^{\circ} \mathrm{C}$ for $24 \mathrm{~h}$.

In the next step the freshly prepared $\mathrm{FeAC}$ was mixed with $1.3 \mathrm{~g} \mathrm{Sr}\left(\mathrm{NO}_{3}\right)_{2}$ in $50 \mathrm{~mL}$ water and $3 \mathrm{~mL} \mathrm{NaOH}(1 \mathrm{M})$ was added under vigorous stirring for $2 \mathrm{~h}$. The obtained mixture was transferred into an autoclave and kept at $180^{\circ} \mathrm{C}$ for $6 \mathrm{~h}$. Finally, the product (FeAC@ $\mathrm{Sr}$ ) was washed three 
times with distilled water by an external magnet and then oven dried at $80^{\circ} \mathrm{C}$ for $24 \mathrm{~h}$.

\section{Removal efficiency}

Adsorption of nitrate was carried out in $100 \mathrm{~mL}$ Erlenmeyer flasks with a defined small amount of nitrate solution near the concerning threshold level for nitrate in drinking water and FeAC@Sr as adsorbent. The mass transfer of nitrate into the sorbent was enhanced by stirring, the adsorbent containing analyte was easily collected using an external magnet and the nitrate residual concentrations were measured with the aid of NitraVer indicator (Hach, Loveland, USA) by using UV-visible spectrophotometer (Cecil Instruments, England) running at $340 \mathrm{~nm}$. The effect of $\mathrm{pH}$ on nitrate adsorption was investigated in the range of $2-10$. The effect of adsorbent dosage (5-120 mg), contact time (5-350 min) and initial concentration of $\mathrm{NO}_{3}^{-}$(15.6 to $197 \mathrm{mg} \mathrm{L}^{-1}$ ) were also investigated. All experiments were done twice and the mean values for duplicate measurements were taken as the final result. The removal efficiency for $\mathrm{NO}_{3}^{-}$- was calculated according to the following equation:

$\operatorname{Removal}(\%)=\frac{c_{i}-c_{e}}{c_{i}} \times 100$

where $c_{i}$ and $c_{e}$ are the initial and final (residual) concentrations of nitrate $\left(\mathrm{mg} \mathrm{L}^{-1}\right)$, respectively. For calculating the adsorption capacity $\left(\mathrm{q}_{\mathrm{t}}, \mathrm{mg} \mathrm{g}^{-1}\right)$ at the $\mathrm{t}$ time (amount of analyte adsorbed per specific amount of adsorbent at equilibrium), the following equation was used:

$\mathrm{q}_{\mathrm{t}}=\frac{\left(\mathrm{c}_{\mathrm{i}}-\mathrm{c}_{\mathrm{t}}\right) \times \mathrm{v}}{\mathrm{m}}$

where $c_{t}$ is nitrate concentration $\left(\mathrm{mg} \mathrm{L}^{-1}\right)$ at a given time $t$ and $\mathrm{v}$ is the aqueous phase volume $(\mathrm{mL})$ and $\mathrm{m}$ is the mass of adsorbent $(\mathrm{g})$. Finally, the amount of adsorbed nitrate at equilibrium $\left(\mathrm{q}_{\mathrm{e}}\right)$ was obtained as follows:

$\mathrm{q}_{\mathrm{e}}=\frac{\left(\mathrm{c}_{\mathrm{i}}-\mathrm{c}_{\mathrm{e}}\right) \times \mathrm{v}}{\mathrm{m}}$

\section{Results and Discussion}

\section{Characterization}

\section{FTIR spectroscopy}

The recorded FTIR spectrum for FeAC@Sr in Figure 1 displays all the adsorption bands of activated carbon at
3494, 1729, and $993 \mathrm{~cm}^{-1}$ assigned to hydroxyl O-H, carbonyl $\mathrm{C}-\mathrm{O}$, and $\mathrm{C}-\mathrm{OH}$ bond vibrations, respectively. ${ }^{9,10}$ The composite exhibited two additional bands, one at $590 \mathrm{~cm}^{-1}$ for iron oxide nanoparticles and another one at $1172 \mathrm{~cm}^{-1}$ corresponding to strontium oxide based nanoparticles of $\mathrm{Sr}-\mathrm{O}(\mathrm{C}-\mathrm{O}-\mathrm{Sr})$ stretching vibration. It is noteworthy that the absence of bonds such as $\mathrm{Fe}-\mathrm{C}$ and $\mathrm{Sr}-\mathrm{C}$ denies the chemical covalent modification of the carbon material and may confirm the electrostatic assemblage of the nanocomposite. These metal oxide containing functional groups $(\mathrm{O}=\mathrm{C}-\mathrm{O}-\mathrm{Sr})$ may adsorb nitrate ions via electrostatic forces, which may enhance the overall adsorption efficiency of the devised material.

\section{BET analysis}

The specific surface area and pore volume of the FeAC@Sr nanocomposite was investigated with BET technique and nitrogen adsorption-desorption profile is shown in Figure 1b. Hence, the newly prepared nanocomposite showed acceptable surface area with BET value of $179 \mathrm{~m}^{2} \mathrm{~g}^{-1}$ and pore size value of $9.2 \mathrm{~nm}$.

\section{XRD diffractometer}

The magnetic FeAC@Sr nanocomposite was characterized with X-ray diffractometry to study the XRD pattern as shown in Figure 1c. XRD pattern shows several characteristics signals that probably are crystalline structure of the magnetic iron oxide $(\mathrm{Fe})$ and strontium nanoparticles $(\mathrm{Sr})$. Based on the XRD reference code 01-076-1849 the signal at $2 \theta$ of $30^{\circ}, 35^{\circ}, 43^{\circ}, 53^{\circ}, 57^{\circ}$ and $63^{\circ}$ are corresponding to cubic magnetic iron oxide and extra signals at $18^{\circ}, 22^{\circ}, 28^{\circ}, 45^{\circ}, 55^{\circ}, 61^{\circ}$ are related to strontium nanostructure. A single broad XRD diffraction at $2 \theta$ of $22^{\circ}$ confirms the amorphous carbon structure for activated carbon. Moreover, the size of the $\mathrm{FeO} / \mathrm{SrO}$ particles were estimated from this diffraction pattern by using Scherrer equation (equations 4 and 5). The average size of the $\mathrm{FeO} / \mathrm{SrO}$ crystal is approximately obtained $162 \mathrm{~nm}$.

$\mathrm{D}=\frac{\mathrm{K} \lambda}{\beta \cos \theta}$

$\beta=\operatorname{FWHM}\left(\frac{\pi}{180}\right)$

where FWHM is the full width at half maximum of the signals, $\lambda$ is the wavelength equal $0.15405 \mathrm{~nm}, \mathrm{D}$ is the size of particles (crystal), $\beta$ is in radian, $\theta$ corresponds to the signals' 2 theta (degree), and $\mathrm{K}$ is a constant equal to 0.96 . 

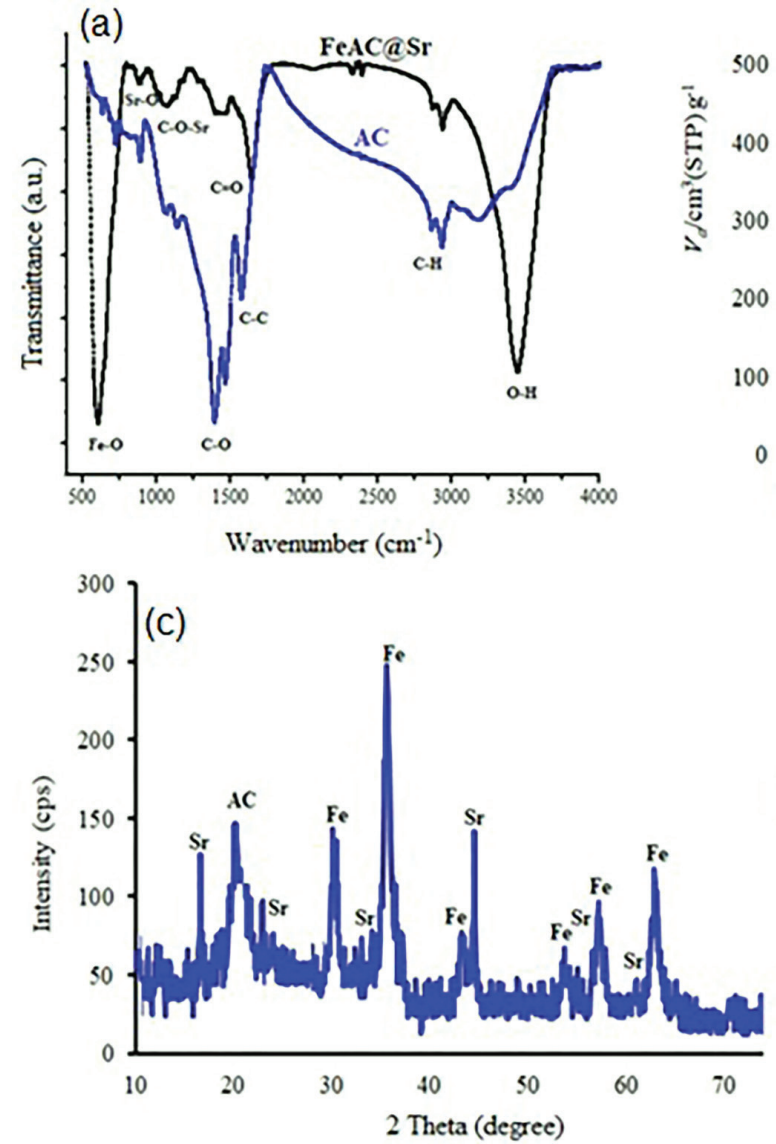

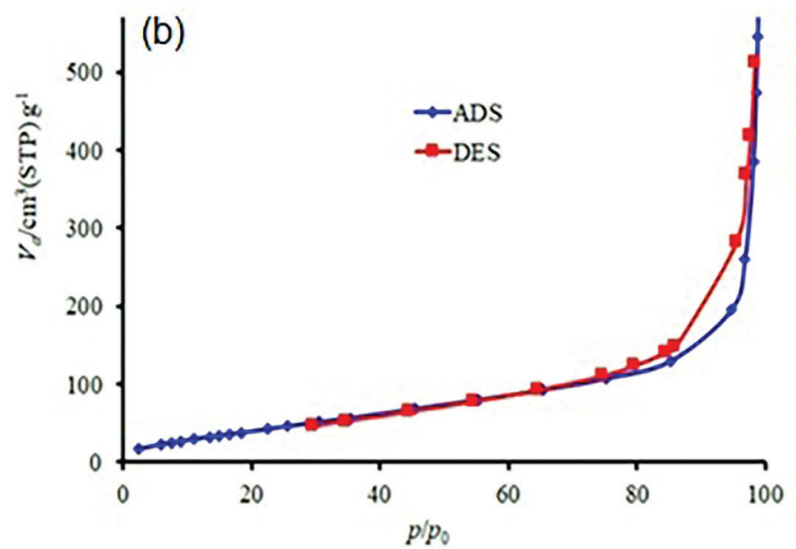

(d)

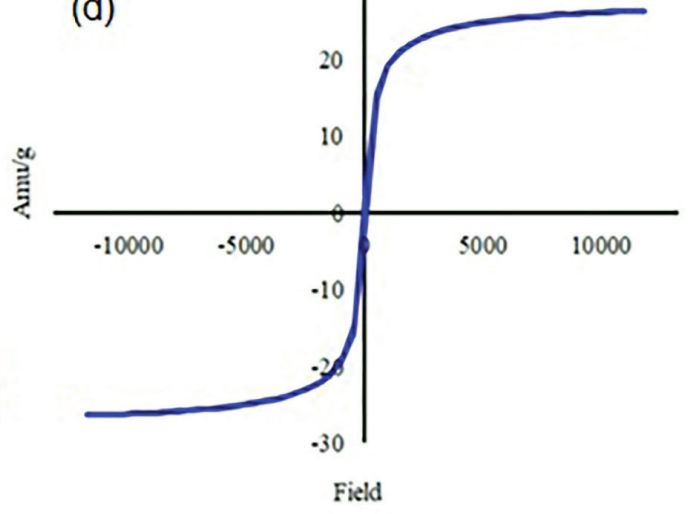

Figure 1. (a) FTIR (KBr) spectrum; (b) BET technique and nitrogen adsorption-desorption profile; (c) XRD pattern; (d) magnetic hysteresis loop for the FeAC@Sr nanocomposite.

\section{VSM analysis}

Magnetic properties of the nanomaterial is an important factor in adsorption/extraction procedures. Magnetic hysteresis loop is obtained by plotting amu g-1 values versus field as in Figure 1d and maximum saturation magnetization value was estimated from plot as $23 \mathrm{amu} \mathrm{g}^{-1}$. This value indicates the nanocomposite is suitable for magnetic separation.

\section{FESEM microscopy}

Figure 2a shows the FESEM micrograph for the plain activated carbon wherein the uniform and porous surface of the material are observed clearly. As shown in Figure $2 b$ the surface of activated carbon is thoroughly covered with particles of iron oxide and strontium based nanoparticles. The non-uniform size and surface of the carbon pores and the distribution of the anchored nanoparticles inside, on the top, and between the pores can be seen as well. ${ }^{23}$ Referring to the high magnification micrograph (Figure 2c), the magnetic tiny nanoparticles appear to be as uniform in size and shape and ordered in distribution ${ }^{31}$ and this is probably unlike strontium nanoparticles which appear to be disordered irregular spherical aggregations..$^{32}$ The light color refers to the carbon matrix region whereas the darker part assigns to the metal oxide based nanoparticles due to the difference in electron penetrability. Figure $2 \mathrm{c}$ indicated that the iron oxide nanoparticles $\left(\mathrm{FeO}_{\mathrm{X}}\right)$ were well dispersed within the pores of the activated carbon substrate which prevented their aggregation or departure from the carbon matrix. ${ }^{33}$ Size of $\mathrm{FeO} / \mathrm{SrO}$ particles were analyzed by Image J software ${ }^{34}$ based on Figure $2 \mathrm{c}$ and average size distribution obtained were $130 \mathrm{~nm}$. Finally, the elemental composition of FeAC@Sr nanocomposite studied by energy-dispersive X-ray spectroscopy (EDX) (Figure 2d) indicated the presence of iron $(45.11 \%, \mathrm{~m} / \mathrm{m})$, oxygen $(20.42 \%, \mathrm{~m} / \mathrm{m})$, carbon $(18.02 \%, \mathrm{~m} / \mathrm{m})$, and strontium elements $(16.45 \%, \mathrm{~m} / \mathrm{m})$ on the surface of the adsorbent.

\section{Optimization of adsorption parameters}

\section{Effect of $\mathrm{pH}$}

The surface charge of nanoparticles is greatly affected by the $\mathrm{pH}$ of solution, so the effect of initial $\mathrm{pH}$ on the adsorption mechanism was studied. Actually, this can be explained by the fact that the surface charge of the sorbent is positive at $\mathrm{pH}$ below the point of zero charge $\left(\mathrm{pH}_{\mathrm{ZPC}}\right)$ and 

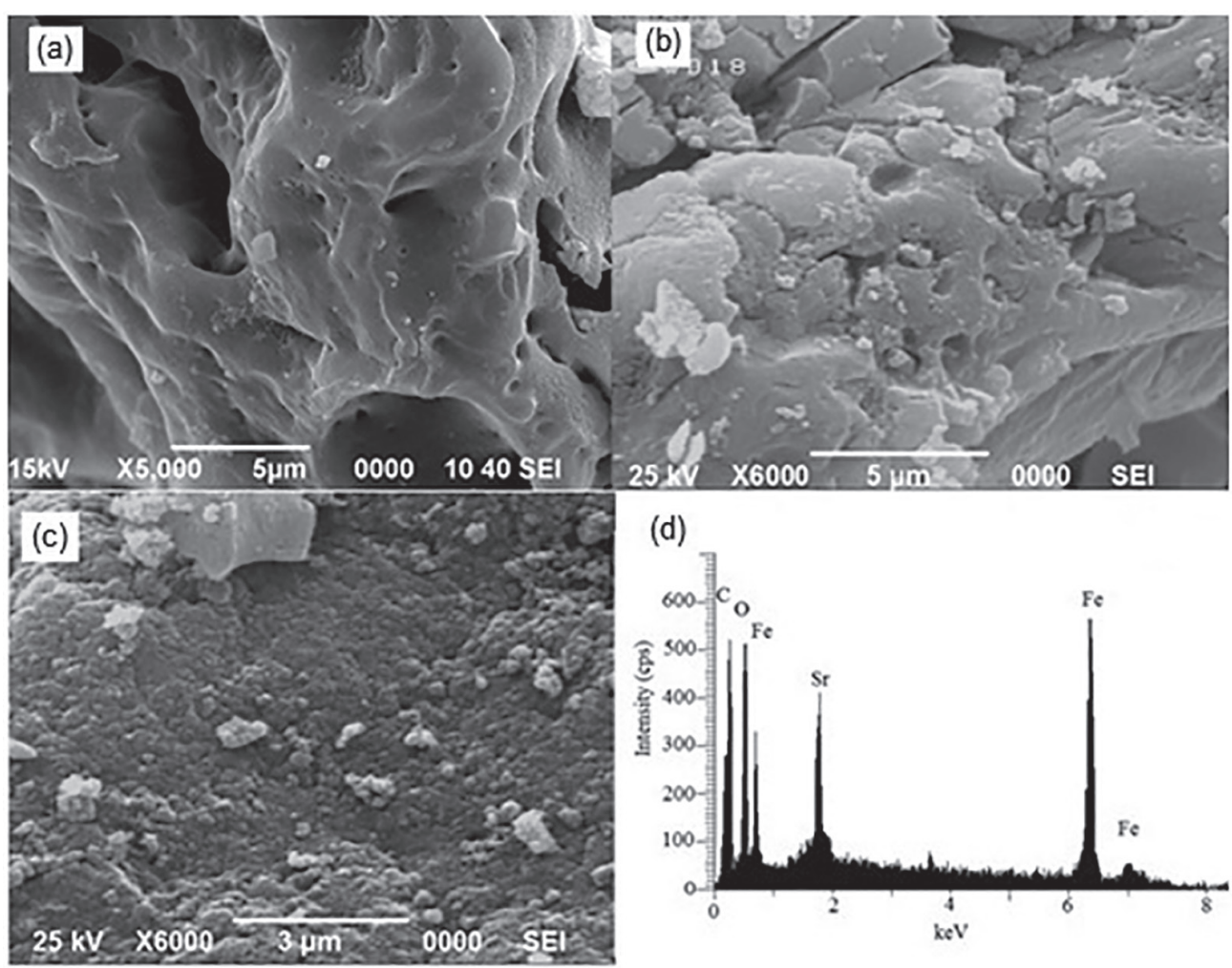

Figure 2. FESEM imaging for (a) plain activated carbon; (b) FeAC@Sr nanocomposite in $5 \mu \mathrm{m}$ scale; (c) FeAC@Sr in $3 \mu \mathrm{m}$ scale and (d) FeAC@Sr EDX spectrum.

negative at $\mathrm{pH}$ higher than $\mathrm{pH}_{\mathrm{ZPC}}$. Electrical surface charge of adsorbent was studied with zeta potential technique to get $\mathrm{pH}_{\mathrm{ZPC}}$, thus its value obtained was $6.1\left(\mathrm{pH}_{\mathrm{ZPC}}=6.1\right)$. As shown in Figure 3a, adsorption efficiency decreased at low and high $\mathrm{pH}$. This is probably due to the positive and negative surface charges of adsorbent at $\mathrm{pH}<\mathrm{pH}_{\mathrm{ZPC}}$ (ca. 2.0-6.1) and $\mathrm{pH}>\mathrm{pH}_{\mathrm{ZPC}}$ (ca. 6.1-10.0), respectively. ${ }^{35,36}$ Negatively charged nitrate species was readily adsorbed via electrostatic attraction at $\mathrm{pH} \mathrm{4-7,} \mathrm{but} \mathrm{the} \mathrm{electrostatic}$ repulsion at high $\mathrm{pH}$ prohibited its adsorption. With increasing in $\mathrm{pH}$ value, the surface charge of metal oxides would be less positive that results in adsorption drop due to the probable electrostatic repulsion between negatively charged nitrate ions and iron oxide surface. ${ }^{17}$ The adsorption efficiency increased tremendously after the first few steps of $\mathrm{pH}$ increase leading to a maximum adsorption achieved at $\mathrm{pH} 4.0 .^{37}$ In conclusion, the main reason for removal of nitrate at $\mathrm{pH}$ ca. 4 is that the negative surface charge of the nanocomposite significantly reduced by the excess of protons present without neutralizing the analyte or causing competition to the binding sites of the adsorbent. As a result, the $\mathrm{pH}$ of the system was set at 4 because in this condition the number of positively charged sites is high enough and favorable for the efficient adsorption of the negatively charged nitrate ions through electrostatic attraction. Similar trends were also reported by other
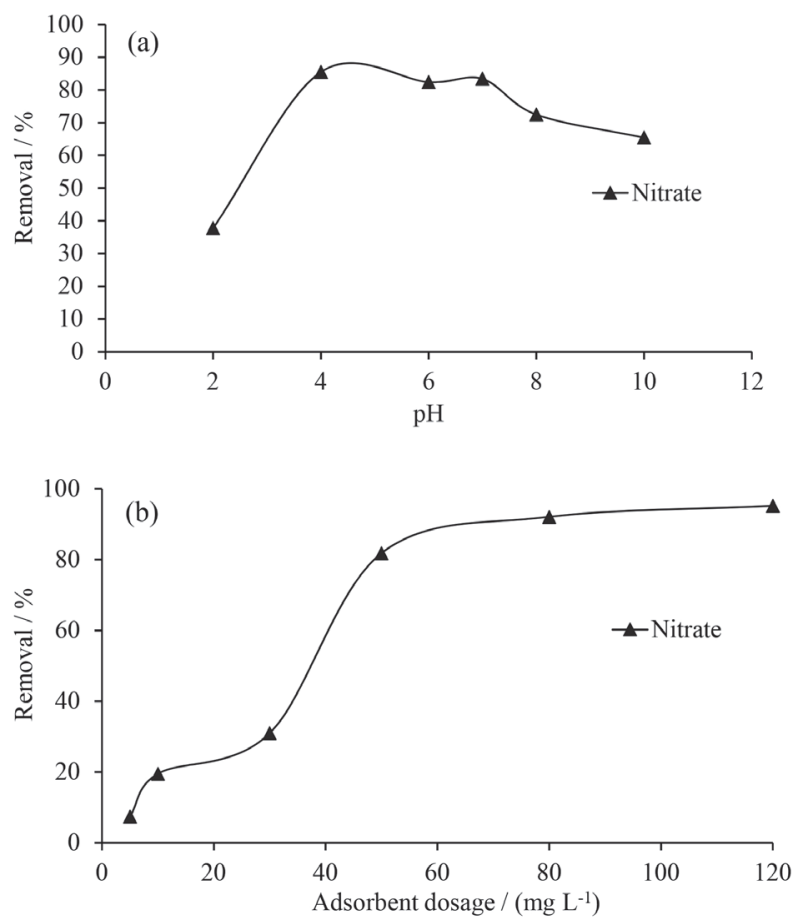

Figure 3. Effect of (a) pH solution and (b) adsorbent dosage on adsorption efficiency (intrinsic concentration of nitrate in underground water was $\left.47 \mathrm{mg} \mathrm{L}^{-1}\right)$.

researchers on the removal of nitrate ions using activated carbon based nanocomposites. . $^{33,38}$ 


\section{Effect of adsorbent dosage}

The effect of adsorbent dosage on nitrate adsorption was studied in order to achieve the maximum adsorption capacity of the devised adsorbent by changing its mass over the range of 5 to $120 \mathrm{mg}$. As shown in Figure 3b, the removal percentage of nitrate increased from 4.85 to $81.01 \%$ as the adsorbent dose increased from 5 to $50 \mathrm{mg}$ to reach a steady state with no further increase. This may be due to adsorption equilibrium being reached. The initial increase in adsorption efficiency may be attributed to the presence of higher number of available adsorption sites for nitrate ions on the solid phase with higher sorbent masses. Thus, $60 \mathrm{mg}$ was chosen as the optimum dose for the further adsorption studies. The percentage of removal reached up to $90.2 \%$ at this dosage of FeAC@Sr.

\section{Adsorption kinetic}

Adsorption of nitrate was studied at different contact times to describe the rate of the sorption process by FeAC@Sr. For this purpose, batch experiments were executed in different contact times until reaching the adsorption equilibrium using $40 \mathrm{~mL}$ nitrate solution and 50 mg FeAC@Sr that mixed together at pH 4.0. The effect of contact time was varied in the range of 5 to $350 \mathrm{~min}$ at a constant initial nitrate concentration $\left(47 \mathrm{mg} \mathrm{L}^{-1}\right.$ in underground water). Figure $4 \mathrm{a}$ is an evidence that shows the removal efficiency increased from 65 to $94 \%$ as the contact time increased from 10 to $180 \mathrm{~min}$ and the equilibrium state was achieved after $90 \mathrm{~min}$ with the examined concentration implying the quickness of the removal process. This trend may be assigned to the longer time available for more removal to occur with greater contact times. It was noticed that adsorption goes on with very fast velocity during the first stages before it declines after equilibrium. ${ }^{21}$

Adsorption process involves the transfer of nitrate ions from the aqueous phase into the solid sorbent. Thus, the adsorption time data were analyzed using the kinetic models of pseudo-first-order and pseudo-second-order to validate the experimental data and find out the adsorption mass transfer rate. ${ }^{39,40}$ The pseudo-first-order and pseudo-secondorder models can be simply denoted by the differential equations 6 and 7 , respectively. ${ }^{41}$

$$
\begin{aligned}
& \ln \left(\mathrm{q}_{\mathrm{e}}-\mathrm{q}_{\mathrm{t}}\right)=\ln \mathrm{q}_{\mathrm{e}}-\mathrm{k}_{1} \mathrm{t} \\
& \frac{\mathrm{t}}{\mathrm{q}_{\mathrm{t}}}=\frac{1}{\mathrm{k}_{2} \mathrm{q}_{\mathrm{e}}^{2}}+\frac{\mathrm{t}}{\mathrm{q}_{\mathrm{e}}}
\end{aligned}
$$

where $\mathrm{q}_{\mathrm{e}}$ and $\mathrm{q}_{\mathrm{t}}$ are the amounts of adsorption capacity $\left(\mathrm{mg} \mathrm{g}^{-1}\right)$ at equilibrium and at a certain time $\mathrm{t}(\mathrm{min})$, respectively. Other variables, $\mathrm{k}_{1}\left(\mathrm{~min}^{-1}\right)$ and $\mathrm{k}_{2}\left(\mathrm{~g} \mathrm{mg}^{-1} \mathrm{~min}^{-1}\right)$
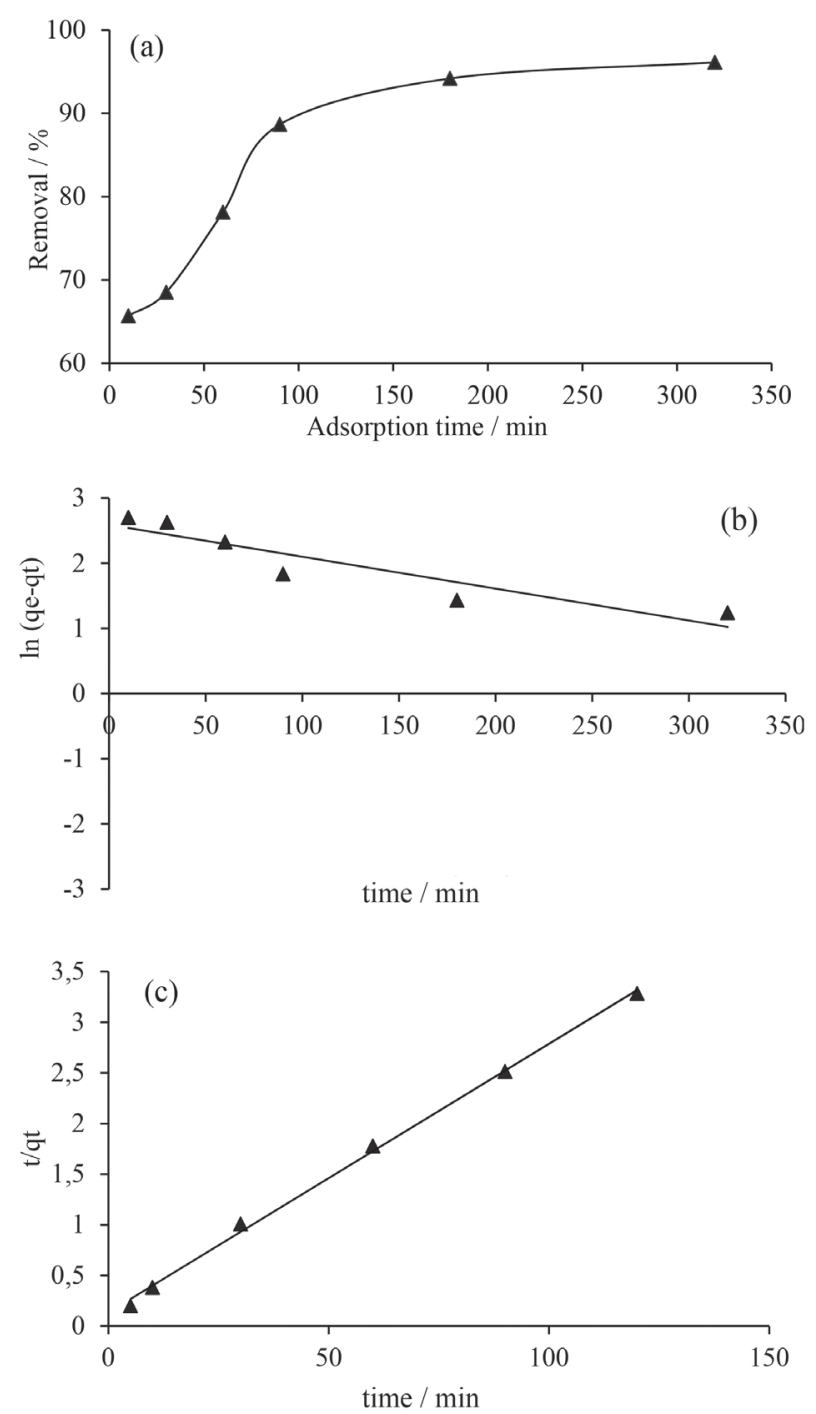

Figure 4. (a) Effect of the contact time on the adsorption of nitrate ions on FeAC@Sr; (b) pseudo-first-order and (c) pseudo-second-order kinetic models (intrinsic concentration of nitrate in underground water was $47 \mathrm{mg} \mathrm{L}^{-1}$ ).

are the pseudo-first and second-order adsorption rate constants, respectively.

The conformity between the predicted values in these models and the experimental data were described by the correlation coefficient $\left(\mathrm{R}^{2}\right)$ and theoretical $\mathrm{q}_{\mathrm{e}}$ value. To find the order of adsorption rate, the correlation coefficient values for the linearity of plots were compared and the higher one indicated the right order for the nitrate adsorption process. The corresponding correlation coefficients and the calculated equilibrium uptakes were obtained from the linear plots in Figures $4 \mathrm{~b}$ and $4 \mathrm{c}$ for the different models. The obtained values are given in Table 1 . Therefore, the kinetic of adsorption was obtained as a pseudo-secondorder corresponding to the better correlation coefficient and the adsorption model with the theoretical $\mathrm{q}_{\mathrm{e}}$ value which is closer to experimental $\mathrm{q}_{\mathrm{e}}$ value. 
Table 1. The kinetic parameters for different adsorption models (nitrate concentration in local underground water was $47 \mathrm{mg} \mathrm{L}^{-1}$ )

\begin{tabular}{|c|c|c|c|c|c|c|c|}
\hline \multirow{3}{*}{ Analyte } & \multirow{3}{*}{$\begin{array}{c}\mathrm{q}_{\mathrm{e}} \text { experimental / } \\
\left(\mathrm{mg} \mathrm{g}^{-1}\right)\end{array}$} & \multicolumn{6}{|c|}{ Model } \\
\hline & & \multicolumn{3}{|c|}{ Pseudo-first-order } & \multicolumn{3}{|c|}{ Pseudo-second-order } \\
\hline & & $\mathrm{R}^{2}$ & $\mathrm{q}_{\mathrm{e}} /\left(\mathrm{mg} \mathrm{g}^{-1}\right)$ & $\mathrm{k}_{1} / \min ^{-1}$ & $\mathrm{R}^{2}$ & $\mathrm{q}_{\mathrm{e}} /\left(\mathrm{mg} \mathrm{g}^{-1}\right)$ & $\mathrm{k}_{2} /\left(\mathrm{g} \mathrm{mg}^{-1} \mathrm{~min}^{-1}\right)$ \\
\hline Nitrate & 41 & 0.802 & 13.08 & 0.004 & 0.998 & 37.74 & 0.0007 \\
\hline
\end{tabular}

$\mathrm{q}_{\mathrm{e}}$ : amount of adsorbed nitrate at equilibrium; $\mathrm{R}^{2}$ : determination coefficient; $\mathrm{k}_{1}, \mathrm{k}_{2}$ : pseudo-first and second-order adsorption rate constants, respectively.

\section{Effect of initial nitrate concentration}

Adsorption equilibrium for nitrate adsorption from aqueous solutions by FeAC@Sr was investigated at a constant contact time but in various initial nitrate concentrations (15.6-197 $\mathrm{mg} \mathrm{L}^{-1}$ ). In the current experiments $50 \mathrm{mg}$ of the adsorbent was mixed with $40 \mathrm{~mL}$ of nitrate solutions at $\mathrm{pH}$ 4.0. Figure 5a revealed an increasing trend from 11.564 to $83.134 \mathrm{mg} \mathrm{g}^{-1}$ (experimental) for the equilibrium of nitrate adsorption with the increase of nitrate concentration from 15.6 to $197.0 \mathrm{mg} \mathrm{L}^{-1}$. It can be seen that the steady state was reached almost at an initial concentration of $97.0 \mathrm{mg} \mathrm{L}^{-1}$ (residual concentration $\left.15.6 \mathrm{mg} \mathrm{L}^{-1}\right)$. In addition, it can be noticed that high
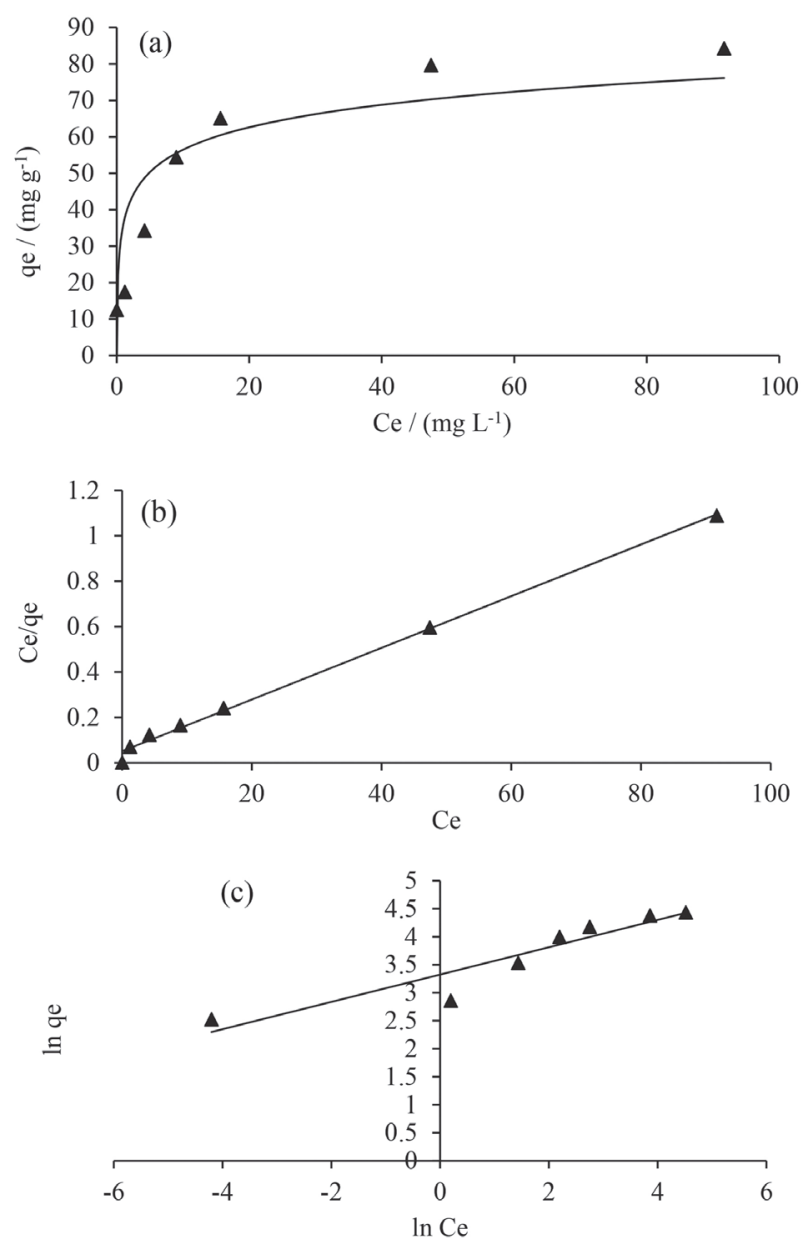

Figure 5. (a) Adsorption equilibrium; (b) Langmuir and (c) Freundlich isotherm models for nitrate adsorption on FeAC@Sr. concentrations hindered further increase of the adsorption rate because of saturation of the adsorption sites. ${ }^{21}$

\section{Adsorption isotherm}

With the change of initial concentration, it is possible to measure the maximum adsorption capacity of the FeAC@Sr adsorbent for nitrate removal. In this study Langmuir and Freundlich models were applied to describe the adsorption capacity and adsorption pattern of FeAC@Sr through analyzing the equilibrium isotherm data. ${ }^{41}$ The linear form of Langmuir and Freundlich models can be expressed according to equations 8 and 9 , respectively. ${ }^{40,42}$

$$
\begin{aligned}
& \frac{\mathrm{C}_{\mathrm{e}}}{\mathrm{q}_{\mathrm{e}}}=\frac{\mathrm{C}_{\mathrm{e}}}{\mathrm{q}_{\mathrm{m}}}+\frac{1}{\mathrm{k}_{\mathrm{L}} \mathrm{q}_{\mathrm{m}}} \\
& \ln \mathrm{q}_{\mathrm{e}}=\ln \mathrm{K}_{\mathrm{F}}+(1 / \mathrm{n}) \ln \mathrm{C}_{\mathrm{e}}
\end{aligned}
$$

where $\mathrm{q}_{\mathrm{e}}$ is the equilibrium adsorption capacity $\left(\mathrm{mg} \mathrm{g}^{-1}\right)$, $\mathrm{q}_{\mathrm{m}}$ is the maximum adsorption capacity to complete a single layer $\left(\mathrm{mg} \mathrm{g}^{-1}\right), \mathrm{C}_{\mathrm{e}}$ is the concentration of unabsorbed nitrate in solution after adsorption $\left(\mathrm{mg} \mathrm{L}^{-1}\right), \mathrm{k}_{\mathrm{L}}$ is Langmuir constant $\left(\mathrm{L} \mathrm{mg}^{-1}\right), \mathrm{K}_{\mathrm{F}}$ is Freundlich constant related to the potential of the adsorbent for up taking nitrate $\left[\left(\mathrm{mg} \mathrm{g}^{-1}\right)\left(\mathrm{L} \mathrm{mg}^{-1}\right)^{1 / \mathrm{n}}\right]$ and $1 / \mathrm{n}$ is a constant describing the energy barrier for adsorption and its feasibility. ${ }^{40}$ These parameters for each isotherm model were calculated from slopes and intercepts in the corresponding graphs in Figures $5 \mathrm{~b}$ and $5 \mathrm{c}$ and their results are presented in Table 2.

By comparing the $\mathrm{R}^{2}$ values for each linear plots and based on the best obtained value, it turned out that nitrate adsorption process follows Langmuir model with a satisfactory maximum adsorption capacity of $87.42 \mathrm{mg} \mathrm{g}^{-1}$. Langmuir model states that interpretation of the adsorption mechanism may be described as a monolayer process with a single layer of adsorbate being bonded onto the adsorbent. ${ }^{42,43}$ However, physisorption mechanism was also suggested for nitrate adsorption since the value of obtained value for free energy was less than $40 \mathrm{~kJ} \mathrm{~mol}^{-1}$. These results were based on equation $10 .{ }^{44}$ Finally, the Dubinin-Radushkevich constant $\left(\mathrm{K}_{\mathrm{ad}}\right)$ value was obtained from well-established DubininRadushkevich model (equation 11), where $\mathrm{q}_{\mathrm{s}}\left(\mathrm{mg} \mathrm{g}^{-1}\right)$ is 
Table 2. The parameters for adsorption isotherms models of nitrate adsorption on FeAC@ $\mathrm{Sr}$

\begin{tabular}{|c|c|c|c|c|c|c|c|}
\hline \multirow{3}{*}{ Analyte } & \multicolumn{7}{|c|}{ Model } \\
\hline & \multicolumn{3}{|c|}{ Langmuir } & \multicolumn{3}{|c|}{ Freundlich } & \multirow{2}{*}{$\frac{\text { Free energy }}{\mathrm{E} /\left(\mathrm{kJ} \mathrm{mol}^{-1}\right)}$} \\
\hline & $\mathrm{q}_{\mathrm{m}} /\left(\mathrm{mg} \mathrm{g}^{-1}\right)$ & $\mathrm{k}_{\mathrm{L}}$ & $\mathrm{R}^{2}$ & $\begin{array}{c}\mathrm{K}_{\mathrm{F}} / \\
{\left[\left(\mathrm{mg} \mathrm{g}^{-1}\right)\left(\mathrm{L} \mathrm{mg}^{-1}\right)^{1 / \mathrm{n}}\right]}\end{array}$ & $\mathrm{n}$ & $\mathrm{R}^{2}$ & \\
\hline Nitrate & 87.42 & 4.48 & 0.9962 & 27.31 & 4.09 & 0.884 & 6.25 \\
\hline
\end{tabular}

FeAC@ Sr: magnetized activated carbon by iron oxide and modified by positively charged strontium based nanoparticles; $\mathrm{q}_{\mathrm{m}}$ : maximum adsorption capacity to complete a single layer; $\mathrm{k}_{\mathrm{L}}$ : Langmuir constant; $\mathrm{R}^{2}$ : determination coefficient; $\mathrm{K}_{\mathrm{F}}$ : Freundlich constant related to the potential of the adsorbent for up taking nitrate; $\mathrm{n}$ : sorption intensity.

theoretical sorption capacity, $\mathrm{R}$ is universal gas constant and $\mathrm{T}(\mathrm{K})$ is temperature.

$\mathrm{E}=\left(2 \mathrm{~K}_{\mathrm{ad}}\right)^{-1 / 2}$

$\ln \mathrm{q}_{\mathrm{e}}=\ln \mathrm{q}_{\mathrm{s}}-\mathrm{K}_{\mathrm{ad}}\left(\varepsilon^{2}\right)$

$\varepsilon=\mathrm{RT} \ln \left[1+\frac{1}{\mathrm{C}_{\mathrm{e}}}\right]$

\section{Effect of interfering ions and regeneration}

The effect of coexisting ions on nitrate removal by FeAC@Sr was studied using various anions and cations including $\mathrm{SO}_{3}{ }^{2-}\left(\mathrm{CuSO}_{3}\right), \mathrm{PO}_{4}{ }^{3-}\left(\mathrm{H}_{2} \mathrm{KPO}_{4}\right), \mathrm{Cl}^{-}\left(\mathrm{FeCl}_{3}\right)$, $\mathrm{Br}^{-}(\mathrm{KBr}), \mathrm{NaCl}, \mathrm{ZnCl}_{2}$ and $\mathrm{Al}\left(\mathrm{NO}_{3}\right)_{3}$. These ions (500 $\mathrm{mg} \mathrm{L}^{-1}$ ) were added into $40 \mathrm{~mL}$ underground water with $47 \mathrm{mg} \mathrm{L}^{-1}$ nitrate concentration. In case the removal percentage does not change significantly it means that the ion is not competitive, but it increases the ionic strength of the solution thus enhances the adsorption capability of the adsorbent. Some ions had inhibitory effects causing decrease in the removal efficiency due to the competitive role and active sites occupied by the ions. After conducting the co-existing ions effect experiments, an efficiency of
83.09\% was obtained for nitrate in the presence of various ions. In further experiment, the nitrate removal efficiency was studied based on multiple adsorption-desorption process. The adsorbed nitrate ions with FeAC@Sr were desorbed using $2 \mathrm{M} \mathrm{NaOH}$ for sequential removal cycles. Hence, appropriate efficiency (> 80\%) was obtained for fifth adsorption-desorption cycles.

\section{Adsorption mechanism}

Proposed adsorption mechanism between nitrate ions and magnetic FeAC@Sr nanocomposite is shown in Figure 6. As can be seen, the electrostatic interactions play an imperative rule in nitrate uptake onto FeAC@Sr. As discussed in "Effect of $\mathrm{pH}$ " sub-section, the adsorbent surface is to change from positive to negative at different $\mathrm{pHs}$. At $\mathrm{pH}>\mathrm{pH}_{\mathrm{ZPC}}(6.1)$, the adsorbent surface is positive $\left(\mathrm{Sr}^{2+}\right.$ and $\left.\mathrm{Fe}^{2+/ 3+}\right)$ and strongly interacts with negative nitrate ions. However, at low pHs probably protonation is more efficient than adsorption. At high pHs, repulsion occurs between negatively changed adsorbent and nitrate ions.

\section{Comparison study}

In this section, adsorption capacity of the prepared nanocomposite was compared with other recently

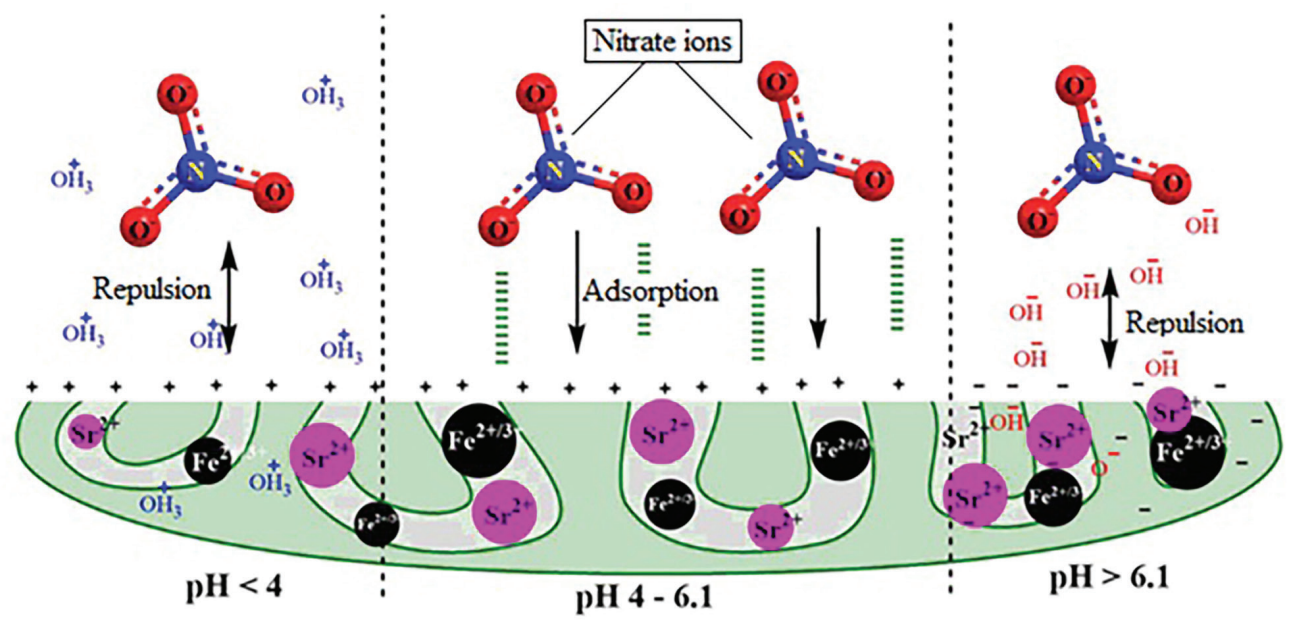

Figure 6. Proposed interaction mechanism between nitrate ions and magnetic adsorbent. 
Table 3. The comparison of adsorption capacity and contact time of different materials for nitrate uptake

\begin{tabular}{|c|c|c|c|c|c|}
\hline Material & $\mathrm{pH}$ & Temperature $/{ }^{\circ} \mathrm{C}$ & time / min & $\mathrm{q}_{\mathrm{e}} /\left(\mathrm{mg} \mathrm{g}^{-1}\right)$ & Reference \\
\hline FeAC@Sr & 4 & 25 & 90 & 87.42 & this study \\
\hline Graphene lanthanum & 6.5 & 25 & 90 & 138.8 & 4 \\
\hline Activated carbon & 4 & 25 & 150 & 11.2 & 45 \\
\hline Chitosan & - & 30 & 200 & 3.4 & 46 \\
\hline Lignocellulose resins & - & - & 60 & 53.18 & 47 \\
\hline Anionic bio-graphene & 7.7 & 25 & 60 & 182.5 & 48 \\
\hline
\end{tabular}

$\mathrm{q}_{\mathrm{e}}$ : amount of adsorbed nitrate at equilibrium; FeAC@Sr: magnetized activated carbon by iron oxide and modified by positively charged strontium based nanoparticles.

introduced adsorbents for nitrate ions uptake (Table 3). Comparing the adsorbents, the FeAC@Sr showed high sorption capacity and short time as adsorption compared with plain activated carbon, chitosan and lignocellulose resins. Anionic bio-graphene and magnetic lanthanum graphene adsorbents provided high adsorption capacity for adsorbing nitrate ions from aqueous solution as compared with FeAC@Sr. This is probably due to matrices of well water that affected the adsorption capacity.

\section{Conclusions}

In this study, the FeAC@Sr was synthesized as an efficient nanocomposite and used for the removal of nitrate ions from underground water. The adsorption experiment of nitrate was conducted under batch mode at $\mathrm{pH}$ 4.0. The adsorption process was checked using Langmuir and Freundlich isotherm models. The nitrate adsorption was well fitted by Langmuir isotherm with an appropriate adsorption capacity of $87.42 \mathrm{mg} \mathrm{g}^{-1}$. Besides, the adsorption kinetic followed pseudo-second-order rate with higher $\mathrm{R}^{2}(0.998)$ value compared to that of first order model. Hence, Langmuir isotherm and free energy models suggested monolayer pattern for nitrate uptake followed by a physical adsorption mechanism.The magnetic FeAC@Sr nanocomposite exhibited high removal efficiency (82.09\%) toward nitrate in the presence of various anions and cations. Thus, the proposed nanocomposite can be used as a highly recommended alternative sorbent material in underground water remediation.

\section{Acknowledgments}

The authors would like to thank the Nanotechnology Products Laboratory, Reference Food and Drug Control Laboratories (Ministry of Health and Medical Education) and Tehran Province Water \& Wastewater Co. (Tehran, Iran) and Sunway University through internal grant (INT-
2019-SST-RCNMET-02) for the research facilities and financial support.

\section{References}

1. Movassaghi, K.; Hemmatian, Z.; Akbari-adergani, B.; Palmisano, G.; Ann. Chim. 2006, 96, 389.

2. Esmaeili, A.; Moore, F.; Keshavarzi, B.; Environ. Earth Sci. 2014, 72, 2511.

3. Stayner, L. T.; Almberg, K.; Jones, R.; Graber, J.; Pedersen, M.; Turyk, M.; Environ. Res. 2017, 152, 294.

4. Nodeh, H. R.; Sereshti, H.; Afsharian, E. Z.; Nouri, N.; J. Environ. Manage. 2017, 197, 265.

5. Kalantary, R. R.; Dehghanifard, E.; Mohseni-Bandpi, A.; Rezaei, L.; Esrafili, A.; Kakavandi, B.; Azari, A.; Desalin. Water Treat. 2016, 57, 16445.

6. Koparal, A. S.; Öğütveren, Ü. B.; J. Hazard. Mater. 2002, 89, 83.

7. Mizuta, K.; Matsumoto, T.; Hatate, Y.; Nishihara, K.; Nakanishi, T.; Bioresour. Technol. 2004, 95, 255.

8. Öztürk, N.; Bektaş, T. E.; J. Hazard. Mater. 2004, 112, 155.

9. Bedin, K. C.; Martins, A. C.; Cazetta, A. L.; Pezoti, O.; Almeida, V. C.; Chem. Eng. J. 2016, 286, 476.

10. Kakavandi, B.; Kalantary, R. R.; Farzadkia, M.; Mahvi, A. H.; Esrafili, A.; Azari, A.; Yari, A. R.; Javid, A. B.; J. Environ. Health Sci. Eng. 2014, 12, 115.

11. Zhang, Y.; Song, X. L.; Huang, S. T.; Geng, B. Y.; Chang, C. H.; Sung, I. Y.; Desalin. Water Treat. 2014, 52, 4935.

12. Liu, M.; Wang, Y.; Chen, L.; Zhang, Y.; Lin, Z.; ACS Appl. Mater. Interfaces 2015, 7, 7961.

13. Jin, F.; Liu, Y.; Day, C. M.; Little, S. A.; Carbon 2007, 45, 587.

14. Xing, M.; Xu, L.; Wang, J.; J. Hazard. Mater. 2016, 301, 286.

15. Zhang, D.; Wonsuk, C.; Yugo, O.; Sung-Hak, C.; Hsiu-Pen, L.; Yaw, L.; Yoshihiro, I.; Koji, S.; Nanomaterials 2018, 8, 631.

16. Zhu, H.; Jia, Y.; Wu, X.; Wang, H.; J. Hazard. Mater. 2009, 172, 1591.

17. Dou, X.; Li, R.; Zhao, B.; Liang, W.; J. Hazard. Mater. 2010 , 182,108 . 
18. Sun, Y. P.; Li, X.; Cao, J.; Zhang, W.; Wang, H. P.; Adv. Colloid Interface Sci. 2006, 120, 47.

19. Wang, T.; Lin, J.; Chen, Z.; Megharaj, M.; Naidu, R.; J. Cleaner Prod. 2014, 83, 413.

20. Li, X.; Elliott, D. W.; Zhang, W.; Crit. Rev. Solid State Mater. Sci. 2006, 31, 111.

21. Wu, L.; Liao, L.; Lv, G.; Qin, F.; He, Y.; Wang, X.; J. Hazard. Mater. 2013, 254, 277.

22. Burnside, S.; Moser, J. E.; Brooks, K.; Gra, M.; Cahen, D.; J. Phys. Chem. B 1999, 43, 9328.

23. Keller, A. A.; Garner, K.; Miller, R. J.; Lenihan, H. S.; PLoS One 2012, 7, 43983.

24. Shahabuddin, S.; Sarih, N. M.; Kamboh, M. A.; Nodeh, H. R.; Mohamad, S.; Polymers 2016, 8, 305.

25. Hu, C.; Lu, T.; Chen, F.; Zhang, R.; J. Chin. Adv. Mater. Soc. 2013, 1, 21.

26. Uskokovic, V.; Kosak, A.; Drofenik, M.; Int. J. Appl. Ceram. Technol. 2006, 3, 134.

27. Zhao, J.; Yuzhong, N.; Bing, R.; Hou, C.; Chem. Eng. J. 2018 , 347, 574.

28. Yang, N.; Zhu, S.; Zhang, D.; Xu, S.; Mater. Lett. 2008, 62, 645.

29. Ponder, S. M.; Darab, J. G.; Mallouk, T. E.; Environ. Sci. Technol. 2000, 34, 2564.

30. Rajabalizadeh, Z.; Seifzadeh, D.; Surf. Coat. Technol. 2016, $304,450$.

31. Ghasemi, A.; Liu, X.; Morisako, A.; IEEE Trans. Magn. 2009 , 45, 4420.

32. Zhao, D.; Li, Q.; Ye, Y.; Zhang, C.; Synth. Met. 2010, $160,866$.

33. Zhu, X.; Liu, Y.; Zhou, C.; Zhang, S.; Chen, J.; ACS Sustainable Chem. Eng. 2014, 2, 969.

34. ImageJ Fiji 1.51; Wayne Rasband, USA, 2017.
35. Rezvani, M.; Najafpou, G.; Mohammadi, M.; Zare, H.; Turk. J. Biol. 2017, 41, 268.

36. Taghavi, M.; Zazouli, M. A.; Yousefi, Z.; Akbari-adergani, B.; Environ. Monit. Assess. 2015, 187, 682.

37. Rajabi, A. A.; Yamini, Y.; Faraji, M.; Nourmohammadian, F.; Nanochem. Res. 2016, 1, 49.

38. Demiral, H.; Gündüzoğlu, G.; Bioresour. Technol. 2010, 101, 1675.

39. Katal, R.; Baei, M. S.; Rahmati, H. T.; J. Ind. Eng. Chem. 2012 , $18,295$.

40. Song, X.; Niu, Y.; Qiu, Z.; Zhang, Z.; Zhou, Y.; Zhao, J.; Chen, H.; Fuel 2017, 206, 80.

41. Nodeh, H. R.; Sereshti, H.; RSC Adv. 2016, 6, 89953.

42. Niu, Y.; Qu, R.; Chen, H.; Mu, L.; Liu, X.; Wang, T.; Zhang, Y.; Sun, C.; J. Hazard. Mater. 2014, 278, 267.

43. Cechinel, M. A. P.; de Souza, A. A. U.; J. Cleaner Prod. 2014, 65, 342 .

44. Wang, W.; Li, M.; Zeng, Q.; Trans. Nonferrous Met. Soc. China 2012, 22, 2831.

45. Kilpima, S.; Runtti, H.; Kangas, T.; Lassi, U.; Kuokkanen, T.; J. Ind. Eng. Chem. 2015, 21, 1364.

46. Kim, J. Y.; Balathanigaimani, M. S.; Hee, M.; Water, Air, Soil Pollut. 2015, 226, 431.

47. Tariq, B. M.; Salmiaton, A.; Idris, A.; Harun, R.; Desalin. Water Treat. 2017, 62, 456.

48. Ghadiri, S. K.; Nasseri, S.; Nabizadeh, R.; Khoobi, M.; Nazmara, S.; Mahvi, A. H.; J. Mol. Liq. 2017, 242, 1117.

Submitted: January 8, 2019

Published online: June 17, 2019 